\title{
Antimicrobial and Cytotoxic Potential of Crude Extracts from Culturable Fungal Endophytes Associated with the Mangrove Species Rhizophora stylosa and R. mucronata in the South China Sea
}

Jing Xu ( $\square$ happyjing3@163.com )

Key Laboratory of Advanced Materials of Tropical Island Resources of Ministry of Education, School of Chemical Engineering and Technology, Hainan University, Haikou 570228, P. R. China Jing Zhou

Key Laboratory of Advanced Materials of Tropical Island Resources of Ministry of Education, School of Chemical Engineering and Technology, Hainan University, Haikou 570228, P. R. China

\section{Research Article}

Keywords: R. stylosa, R. mucronata, Endophytic Fungus, Antimicrobial Activity, Cytotoxic Activity

Posted Date: March 2nd, 2021

DOl: https://doi.org/10.21203/rs.3.rs-249721/v1

License: (c) (1) This work is licensed under a Creative Commons Attribution 4.0 International License.

Read Full License 
Antimicrobial and Cytotoxic Potential of Crude Extracts from Culturable Fungal Endophytes Associated with the Mangrove Species Rhizophora stylosa and $R$. mucronata in the South China Sea

Jing Zhou ${ }^{\mathrm{a}, \mathrm{b}}$, Jing $X u^{\mathrm{a}, \mathrm{b}, \text { * }}$

${ }^{a}$ Key Laboratory of Advanced Materials of Tropical Island Resources of Ministry of Education, School of Chemical Engineering and Technology, Hainan University, Haikou 570228, P. R. China.

${ }^{\mathrm{b}}$ Hainan Provincial Fine Chemical Engineering Research Center, School of Life and Pharmaceutical Sciences, Hainan University, Haikou 570228, P. R. China

Prof. Dr. Jing Xu, Tel.: ++86-898-6627-9226, Fax: ++86-898-6627-9010, E-mail: happyjing3@163.com 


\section{Abstract}

Our research evaluated the antimicrobial and cytotoxic activities of crude extracts of endophytic fungi from $R$. stylosa and $R$. mucronate. 46 fungal isolates were cultured on the four different mediums, namely Dextrose Agar (PDA), Czapek's Agar (CZA), Rice Medium (RM) and Grain Medium (GM), and harvested by ethyl acetate solvent at 40 days. The extracts were tested for antimicrobial activity by the microdilution method against Gram-negative bacteria Pseudomons adaceae (PA), Gram-positive bacteria Enterococcus faecalis (EF), Methicillin-resistant Staphylococcus aureus (MRSA) and pathogenic fungus Monilia albican (MA). Cytotoxic activity of the extracts was evaluated by MTT assay using human lung cancer cells A549, human cervical carcinoma cells Hela, and human hepatocellular cells HepG2. The results showed that rice medium could promote the secretion of antimicrobial and anti-tumor secondary metabolites of endophytic fungi in comparison with the other cultivation media. 17 strains (68\%) from R. stylosa exhibited inhibition effects on indicators, especially $N$. protearum HHL46 which could inhibit the growth of four microbes with the MIC values reaching $0.0625 \mathrm{mg} / \mathrm{mL} .15$ strains (71.4\%) from $R$. mucronata displayed activities against human pathogenic microbes, especially Pestalotiopsis sp. HQD6 and $N$. protearum HQD5 which could resist the growth of four microbial with MIC values ranging from 0.015 to $1 \mathrm{mg} / \mathrm{mL}$. In cytotoxic assay, the extracts of 10 strains $(40 \%), 9$ strains (40\%) and 13 strains (52\%) from $R$. stylosa and 13 strains (61.9\%), 10 stains (47.6\%) and 10 stains (47.6\%) in R. mucronata displayed the cytotoxicity against A549, Hela and HepG2 cancer cells with cells viability value $\leq 50 \%$, respectively. 
Neopestalotiopsis protearum HHL46, Phomopsis longicolla HHL50, Botryosphaeria fusispora HQD83, Fusarium verticillioides HQD48 and Pestalotiopsis sp. HQD6 displayed significant antitumor activity with $\mathrm{IC}_{50}$ values below the $20 \mu \mathrm{g} / \mathrm{mL}$. These results highlighted the antimicrobial and anti-tumor potential of endophytic fungi from $R$. stylosa and R. mucronata and the possibility to be exploited for their antimicrobial and cytotoxic agents.

\section{Keywords}

R. stylosa; R. mucronata; Endophytic Fungus; Antimicrobial Activity; Cytotoxic Activity

\section{Introduction}

Mangrove forests are complex ecosystems that distributed in the intertidal zone of tropical and subtropical coasts, which not only refers to mangrove plants, but also include the diverse groups of microorganisms formed by abundant biological communities ${ }^{1}$. There are 61 species of true mangrove plants in the world, belonging to 14 families and 21 genus. China has 26 species, and 24 of them have been documented in Hainan ${ }^{2}$. Mangrove endophytic fungi tolerant to numerous stresses, such as high salinity, high temperature, extreme tides, oxygen pressure, high humidity, and light and air limitations, have evolved unique metabolic pathways for the purposes of the competition of nutrition and space in extremely fierce niche, which will inevitably render them capable of exhibit excellent biological activity via producing impressive numbers of metabolites with special biological functions ${ }^{3,4}$. Rivai et al studied the antimicrobial activities of endophytic fungi from $R$. mucronata and ethyl acetate extract 
of 14 strains $(64.3 \%)$ showed activity on test microbes of S. aureus, E. coli, and $C$. albicans $^{5}$. Cladosporium sp. isolated from Thespesia populneoides and Xylaria sp. isolated from Acanthus ilicifolius were reported to exhibit Gram-positive and Gramnegative bacteria inhibition towards Bacillus subtilis, Pseudomonas aeruginosa, Escherichia coli and Staphylococcus aureus. Additionally, most extracts of 84 endophytic fungi from 10 different mangrove hosts belonging to seven families, which were Rhizophoraceae (Rhizophora apiculata, R. mucronata, Ceriops decandra), Sonneratiaceae (Sonneratia alba), Combretaceae (Lumnitzera littorea), Avicenniaceae (Avicennia alba), Acanthaceae (Acanthus ilicifolius), Meliaceae (Xylocarpus granatum and Xylocarpus moluccensis) and Malvaceae (Thespesia populneoides) and showed cytotoxicity against some cancer cell lines, including A375 (human malignant melanoma), SW620 (human colorectal adenocarcinoma), Kato III (human gastric carcinoma), HepG2 (human liver hepatoblastoma) and Jurkat (humanacute T cell leukemia) ${ }^{6}$. Extracts of 9 endophytic fungal isolates (64.3\%) from $R$. mucronata can inhibit the growth of tested bacterium and fungi, of 12 isolates (85.7\%) were cytotoxic (cell viability $<50 \%$ ) against T47D cells ${ }^{5}$.

Rhizophora is one of the most conspicuous genera of the most widespread mangrove family, the Rhizophoraceae. There were 66 genus endophytic fungi were isolated from plants of the genus Rhizophora, such as Aspergillus, Cladosporium, Chaetomium, Fusarium, Lasiodiplodia, Penicillium, Pestalotiopsis, Phomopsis, Phoma, Phyllosticta, Trichoderma, and more than 195 natural products, including alkaloids, terpenoids, coumarins, chromones, quinones, peptides, phenolic acids, 
lactones were identified, and cytotoxicity was found to be the most notable bioactivities of secondary metabolites isolated ${ }^{2}$. Among them, unprecedented scaffolds indolediterpenes rhizovarins A-C isolated from Mucor irregularis QEN-189 in R. stylosawere against human cancer HL-60 and A-549 cell lines with IC 50 values ranging from 5 to $15 \mu \mathrm{M}$ and they are novel inhibitors of the $\mathrm{Wnt} / \beta$-catenin pathway in breast cancer cells ${ }^{7,8,9}$.A novel cytochalasin, which was found in endophytic fungus Phomopsis sp. derived from Kandelia candel, can effectively induce the apoptosis and inhibit the migration of human lung cancer cells A549 according to significantly increased the protein expression of Bax, p53 and cleaved Caspase-3, and increased ratio of the antiapoptosis proteins of $\mathrm{Bax} / \mathrm{Bcl}-2^{10,} 11$. In addition, demethylincisterol $\mathrm{A}_{3}$ was as a selective inhibitor of a classical non-receptor protein tyrosine phosphatase Shp2 and isolated from $R$. mucronata endophytic Pestalotiopsis sp. HQD6 ${ }^{12,13}$. New polyketide derivatives pestalpolyol I was obtained from extracts of the endophytic fungus $P$. clavispora isolated from $R$. harrisonii exhibited strong cytotoxicity against the mouse lymphoma cell line L5178Y with an $\mathrm{IC}_{50}$ value of $4.10 \mu \mathrm{M}^{14}$.

During our previous work on biological potentials of endophytic fungi of mangrove-derived, we isolated and identified the endphytic fungi from the mangrove $R$. stylosa and $R$. mucronata and their antioxidant activities were evaluated ${ }^{15}$. In this study, we continuous investigated on antimicrobial and cytotoxic activities of endophytic fungi isolated from $R$. stylosa and $R$. mucronat. We tried to promote the secretion of antibacterial and antitumor substances of our fungal isolates by using four different culture medium. Four microbial indicator strains (PA, EF, MRSA and MA) 
and three human cancer cell lines (Hela, A549 and HepG2) were adopted for antimicrobial and cytotoxic tests, respectively. This study aims to provide complete information on the in vitro potential of the endophytic fungi of these two hosts as producers of antimicrobial and cytotoxic activities.

\section{Results}

\section{Antimicrobial activity of fungal extracts}

A total of 46 fungal extracts assayed, 32 extracts (69.6\%) showed antimicrobial activity against, at least, one of the indicator pathogenic microbes tested (Tables 1 and 2). The antimicrobial activity of the same isolated fungal strain was significantly different when cultured on kinds of mediums.

Of the endophytic fungi isolated from $R$. stylosa (25 isolates, Table 1), RM were determined to be more suitable for antibiotic production in fungal isolates than other three mediums. Of these, 13 strains cultured on RM (52\%) exhibited antimicrobial activity using concentration of the extracts $10 \mathrm{mg} / \mathrm{mL}$, and among them, 7 strains had stronger inhibitory effects on MRSA with MIC values less than $0.5 \mathrm{mg} / \mathrm{mL}$. HHL55 showed the broadest antimicrobial spectrum against four indicator test microorganisms, CZA culture of HHL55 was found to show the most potent antimicrobial activity against PA with MIC value of $0.031 \mathrm{mg} / \mathrm{mL}$. Only 2 strains fermented on the GM displayed low inhibitory activity with MIC value of $1 \mathrm{mg} / \mathrm{mL}$. In addition, three culture media of HHL94, HHL64 and HHL82, showed inhibitory effect on three indicator test microorganisms.

Of the endophytic fungi isolated from $R$. mucronata (21 isolates, Table 2), most 
of the fungal strains (15 isolates, 71.4\%) exhibited antimicrobial activity. A high growth inhibition rate were detected from the fungal extracts cultured on CZA (10 isolates, 47.6\%) and RM (10 isolates, 47.6\%), in comparison with PDA (7 isolates, 33.3\%) and GM (2 isolates, $9.5 \%$ ) at the concentration of $10 \mathrm{mg} / \mathrm{mL}$ selected. RM of 9 isolates and CZA of 3 isolates showed strong inhibitory effects on MRSA with MIC values less than $0.5 \mathrm{mg} / \mathrm{mL}$. Only extract of HQD20 cultivated on the GM inhibited the growth the MRSA and MA. Moreover, HQD6 and HQD5 displayed antimicrobial activity against the growth of four indicator microorganisms tested with MIC values ranging from 0.015 to $1 \mathrm{mg} / \mathrm{mL}$.

\section{Cytotoxicity of fungal extracts}

Cytotoxic effect of $R$. stylosa and $R$. mucronata endophytic fungal extracts were tested against HeLa, A549 and HepG2 cells using MTT colorimetric assay. Half inhibitory concentration $\left(\mathrm{IC}_{50}\right)$ values were shown in Table 3 and 4 . Results are represented as the means \pm standard deviation of experiments performed triplication. Cell viability using different concentrations of these extracts after $24 \mathrm{~h}$ of treatment were determined (Fig. 1 and 2). The cytotoxicity of fungal extracts showed a dosedependent relationship.

As shown in Table 3, of the endophytic fungi isolated from $R$. stylosa, extracts of 10 isolates (40\%) tested were cytotoxic and exhibited a percentage of viability A549 cells value $\leq 50 \%$. Four extracts (HHL75, HHL46, HHL10 and HHL50) IC50 values were lower than $100 \mu \mathrm{g} / \mathrm{mL}$ ( $\mathrm{IC}_{50}$ values of $64.38 \pm 3.40,11.65 \pm 0.34,97.21 \pm 1.36$ and $16.31 \pm 0.36 \mu \mathrm{g} / \mathrm{mL}$, respectively), suggesting the cytotoxic potential of these four fungal 
isolates (Fig. 1 A, B, C and D). Extracts of 9 isolates (36\%) showed cytotoxicity and displayed a percentage of viability Hela cells value $\leq 50 \%$. Especially, HHL46, HHL82, HHL52 and HHL50 extracts showed the most significant cytotoxic effect, with IC $_{50}$ values of $31.03 \pm 1.21,14.38 \pm 1.84,70.55 \pm 1.37$ and $73.18 \pm 1.64$, which were lower than $100 \mu \mathrm{g} / \mathrm{mL}$ (Fig. 1 E, F, G and H). Extracts of 13 isolates (52\%) showed cytotoxicity against HepG2 cells, amongst 7 extracts (HHL61, HHL75, HHL46, HHL10, HHL52 and HHL50) could significantly suppress the proliferation of HepG2 cells with $\mathrm{IC}_{50}$ below $100 \mu \mathrm{g} / \mathrm{mL}$ (Fig. $1 \mathrm{I}, \mathrm{J}$ and K).

As shown in Table 4, of the endophytic fungi isolated from $R$. mucronata, extracts of 13 isolates (61.9\%) displayed cytotoxic activity on A549 cells, 10 isolates (47.6\%) on Hela cells, and 10 isolates (47.6\%) on HepG2 cells. Of which, 9 extracts (HQD83, HQD33, HQD28, HQD48, HQD41, HQD5, HQD1, HQD6 and HQD8) exhibited significant cytotoxicity against A549 cells with IC50 less than $100 \mu \mathrm{g} / \mathrm{mL}$ (Fig. 2 A, B, C and D). 4 extracts (HQD83, HQD48, HQD5 and HQD20) showed strong cytotoxic effect against the Hela cell line with $\mathrm{IC}_{50}$ values below $100 \mu \mathrm{g} / \mathrm{mL}$ (Fig. $2 \mathrm{E}, \mathrm{F}, \mathrm{G}$ and H). 7 extracts (HQD83, HQD28, HQD48, HQD41, HQD5, HQD6 and HQD57) that were potent ( $\mathrm{IC}_{50}<100 \mu \mathrm{g} / \mathrm{mL}$ ) against HepG2 cells (Fig. 1 I J K and L).

In an attempt to promote the antitumor substances production, four different media were adopted for the fungal isolates cultivation to activate the biosynthetic silence gene expression. We found that extracts of 1 isolate (HQD28) cultured on PDA, 1 isolate (HQD48) cultured on CZA, 3 isolates (HHL82, HQD52 and HQD6) cultured on RM and 4 isolates (HHL46, HQD48, HQD5 and HQD8) cultured 
on GM exhibited significant anti-proliferative activity against at least one of the tested carcinoma cells with $\mathrm{IC}_{50}<20 \mu \mathrm{g} / \mathrm{mL}$. GM culture of $R$. stylosa endophytic HHL46, RM culture of HHL61 and HHL82 were most effective against A549, Hela and HepG2 with $\mathrm{IC}_{50}$ values of $14.38 \pm 1.84 \mu \mathrm{g} / \mathrm{mL}, 23.17 \pm 4.26 \mu \mathrm{g} / \mathrm{mL}$ and $14.38 \pm 1.84 \mu \mathrm{g} / \mathrm{mL}$, respectively (Table 3). The extracts from CZA culture of $R$. mucronata endophytic HQD48, RM culture of HQD20 and HQD6 exhibited the highest cytotoxicity towards A549, Hela and HepG2 with $\mathrm{IC}_{50}$ values of $4.83 \pm 1.61 \mu \mathrm{g} / \mathrm{mL}, 14.38 \pm 1.84 \mu \mathrm{g} / \mathrm{mL}$ and $9.58 \pm 0.01 \mu \mathrm{g} / \mathrm{mL}$, respectively (Table 4). The genus Pestalotiopsis and Phomopsis were demonstrated to be a rich source of antitumor secondary metabolites. Notable, RM culture of HQD6 exhibited cytotoxic and antiproliferative effects against three tested cancer cell lines with $\mathrm{IC}_{50}$ values ranged from $9.58 \mu \mathrm{g} / \mathrm{mL}$ to $14.99 \mu \mathrm{g} / \mathrm{mL}$.

\section{Discussion}

Infectious diseases, including bacterial infections, pose a serious threat to global health and drug resistance ${ }^{16,17}$. Unfortunately, there has been resistance detected against every antibiotic on the market and if antibiotic resistance is not remedied pathogenic bacteria will once again become one of the leading causes of mortality with an estimated yearly death toll of $\sim 10$ million by $2050^{18}$. The development of new antimicrobial agents is pointed out as one of the effective solutions to address this problem ${ }^{19,20}$. As a promising source of diverse and structurally unprecedented bioactive natural products, mangrove-derived endophytic fungi are unquestionable continuously attracted considerable attention ${ }^{21,22}$. In our current study, of 46 endophytic fungi strains investigated, 32 extracts (69.6\%) exhibited antimicrobial activity, which is in 
consistent with the findings of previous study of Buatong et al. ${ }^{23}$.that $61.3 \%$ mangrove fungal endophytes produced inhibitory compounds.

Cancer-related death is one of most the significant threats to human health worldwide, it is estimated 12.7 million new cases and 7.6 million cancer death each year ${ }^{24}$. At present, the primary treatment method for cancers is combine removing the tumour with the anesthetic agents after surgery ${ }^{25}$. Unfortunately, after the surgery process, it is possibly leads to tumour progression cause a large number of tumour cells to be released and due to reducing the activity of T, B and NK lymphocytes in the postoperative period ${ }^{26}$. It has also generated a large body of information that is being harnessed to develop new therapeutic modalities for treating cancer ${ }^{27}$, however, search for cytotoxic agents selectively impact on proliferating cells still play an essential role in tumour treatment ${ }^{28}$. In our study, of 46 endophytic fungi strains investigated, 23 extracts $(50 \%)$ showed cytotoxicity more or less, amongst 21 extracts $(46.65 \%)$ were cytotoxic against A549 cells, 16 extracts (34.78\%) were cytotoxic against Hela cells, 21 extracts (46.65\%) were cytotoxic against HepG cells. That were in accordance with the previous reports, of which 9 endophytic fungi were successfully obtained from the leaves of Ginkgo biloba, the extracts of isolates J-1, J-2 and J-3 markedly inhibited the proliferation of $\mathrm{HeLa}$ cells, promoted their apoptosis and blocked their migration ${ }^{29}$ and 12 isolates extracts $(85.7 \%)$ derived from mangrove Rhizophora mucronata were cytotoxic (cell viability $<50 \%$ ) against T47D cells ${ }^{5}$.

Culture-dependent methods have been developed aimed at substantial increases of biological active secondary metabolites production by any given microorganism ${ }^{30}$. RM 
was demonstrated to have the highest suitability for antibiotic production which 23 extracts $(50 \%)$ were showed antimicrobial activity against at least one of four strains and the extract of HQD1 exhibited antimicrobial activity against MRSA with MIC value of $0.031 \mathrm{mg} / \mathrm{mL}$, which were in accordance with the previous reports of Rivai et $a l^{5}$. RM (11 isolates, 39.13\%) and GM (9 isolates, 19.56\%) were more suitable for antitumor agent production, which agreed with previous reports of GM cultivated Oidiodendron truncatum led to the discovery of potent anticancer agent chetracins B with cytotoxicity against five human cancer lines reaching $\mathrm{nM}$ degree ${ }^{31}$. The variation in the antibiotic and cytotoxic properties among media could possibly be related to the composition of RM and GM activated our isolated fungal biosynthetic gene clusters ${ }^{32}$.

\section{Materials and methods}

Fungal material used. Previously isolated endophytic fungi from healthy roots, stems, leaves, hypocotyls and flowers of $R$. stylosa and $R$. mucronata collected from a specific location $\left(110^{\circ} 32^{\prime}-110^{\circ} 37^{\prime} \mathrm{E}, 19^{\circ} 51^{\prime}-20^{\circ} 01^{\prime} \mathrm{N}\right)$ in Dong Zhai Gang-Mangrove Garden on Hainan Island, China, were used for the present study. These endophytic fungi were identified in combination of morphologic characteristics and $\mathrm{p}$ internal transcribed spacer (ITS) sequences. Their antioxidant capacity have also been demonstrated ${ }^{15}$.

Fermentation and extraction. Fungal isolates were cultured on Petri dishes of potato dextrose agar (PDA) at $28^{\circ} \mathrm{C}$ for 5 days and then inoculated on four different mediums such as PDA, Czapek's Agar (CZA), Rice Medium (RM), Grain Medium (GM) for stationary fermentation. After 40 days, the harvested cultures were extracted by 100 $\mathrm{mL}$ the ethyl acetate and treated in ultrasound at $50^{\circ} \mathrm{C}$ for $1 \mathrm{~h}$, then, filtrated by filter 
paper. Rotary evaporator was used at $50{ }^{\circ} \mathrm{C}$ with low pressure to evaporate the remaining of ethyl acetate. The extracts were dissolved in dimethyl sulfoxide (DMSO, not exceed $1 \%, \mathrm{v} / \mathrm{v}$ ) and stored at $4^{\circ} \mathrm{C}$ until being used.

Screening for antimicrobial activity. The endophytic fungal extracts were tested against Gram-negative bacteria Pseudomons adaceae (PA), Gram-positive bacteria Enterococcus faecalis (EF), Methicillin-resistant Staphylococcus aureus (MRSA) and pathogenic fungus Monilia albican (MA) by microdilution method with some modifications $^{33}$. An aliquot of extract $(2 \mu \mathrm{l})$ was added to $198 \mu \mathrm{l}$ of the indicator strain suspension with a density of $5 \times 10^{6} \mathrm{CFU} / \mathrm{ml}$ into each well of a 96-well microplates. This mixture was then incubated for $24 \mathrm{~h} / 48 \mathrm{~h}$ at $37^{\circ} \mathrm{C} / 28^{\circ} \mathrm{C}$ and the minimum inhibitory concentration (MIC) were recorded. Amphotericin B was used as positive control.

Screening for cytotoxicity. Cytotoxicity was tested by 3-(4,5-dimethylthiazol-2-yl)2,5-diphenyltetrazolium bromide (MTT) method according to our previous report ${ }^{13}$. Human cervical carcinoma cells (HeLa), human lung cancer cells (A549), human hepatoma cells (HepG2) cells were grown in RPMI-1640 culture medium with $200 \mu \mathrm{L} / \mathrm{mL}$ fetal bovine serum (FBS) under a humidified atmosphere of $5 \% \mathrm{CO}_{2}$ and $95 \%$ air at $37{ }^{\circ} \mathrm{C} .100 \mu \mathrm{L}$ cell suspension at a density of $1.5 \times 10^{5}$ cell $\mathrm{mL}^{-1}$ was pipetted into 96-well microtiter plates. Fungi extracts with different concentrations from 100 $\mu \mathrm{g} / \mathrm{mL}$ to $600 \mu \mathrm{g} / \mathrm{mL}$ were added to each well and incubated for $24 \mathrm{~h}$ at the above conditions in a $\mathrm{CO}_{2}$-incubator. $20 \mu \mathrm{L}$ MTT $(5 \mathrm{mg} / \mathrm{mL})$ was added to each well and plates were further incubated for 3 h. $200 \mu \mathrm{L}$ DMSO was added to dissolve the formazan 
crystals. The absorbance was then measured at $570 \mathrm{~nm}$ by a microplate reader. The cell inhibition rate $(\% \mathrm{IR})$ was calculated by the equation as follows: $\% \mathrm{IR}=\left[\left(A_{\text {bla }}-A_{\text {sam }}\right) / A_{b l a}\right]$ $\times 100$, where $A_{\text {bla }}$ is the absorbance of the blank, $A_{\text {sam }}$ is the absorbance of the test compounds. The $\mathrm{IC}_{50}$ value was calculated from the dose-response relationship. Doxirubicin was used as the positive control.

\section{Conclusion}

To date, there are few systematic studies on the antimicrobial and antitumor potential on mangrove endophytic fungi. Our study indicated that the antimicrobial and cytotoxic activities of mangrove endophytic fungi extracts grown on four media showed distinguishable differences of activities and revealed the RM could promote the secretion of bioactive secondary metabolites. Neopestalotiopsis protearum HQD5 and Pestalotiopsis sp. HQD6 showed the potent antimicrobial activity, Neopestalotiopsis protearum HHL46, Phomopsis longicolla HHL50, Botryosphaeria fusispora HQD83, Fusarium verticillioides HQD48 and Pestalotiopsis sp. HQD6 displayed significant antitumor activity. Considering that, these fungi could be further explored for the characterization of antimicrobial and cytotoxic secondary metabolites which could explain the significant biological activities of the abovementioned fungal strain.

\section{References}

1. Xu, J. Natural Products of mangrove-derived microbes. In: Huo ZG (eds). Science Press, Beijing, pp 2-3 (2015a).

2. Zhou, J., Xu, J. Chemistry and biodiversity of Rhizophora-derived endophytic fungi. In: Sharma S (eds). Mangrove ecosystem ecology and function. InTechOpen, London, pp 163-186 
(2015a).

3. Xu, J. Biomolecules produced by mangrove-associated microbes. Curr. Med. Chem. 18, 5224$5266(2011)$.

4. Xu, J. Bioactive natural products derived from ,mangrove-associated microbes. RSC. Adv. 5, 841-892 (2015b).

5. Rivail, H. Handayani, D. \& Tifani, R. Screening of Antimicrobial and Cytotoxic Activities of Endophytic Fungi Isolated from Mangrove Plant Rhizophora mucronata Lam. J. Phar. Sci. Med. 3, 9-20 (2018).

6. Chaeprasert, S. Piapukiew J. \& Whalley, AJS. Endophytic fungi from mangrove plant species of Thailand: their antimicrobial and anticancer potentials. Bot. Mar. 53, 555-564 (2010).

7. Gao S. S., Li X. M. \& Katherine, W. Rhizovarins A-F, Indole-diterpenes from the mangrovederived endophytic fungus Mucor irregularis QEN-189. J. Nat. Prod. 79, 1-8 (2016).

8. De Jesus, A. E., Steyn, P. S. \& Van Heerden, F. R. Tremorgenic mycotoxins from Penicillium crustosum. Structure elucidation and absolute configuration of penitrems B-F. J. Chem Soc. 1, $1847-1856(1983)$.

9. Sallam, A. A., Ayoub, N. M., Foudah, A. I., Gissendanner, C. R. \& Meyer, S. A. Indole diterpene alkaloids as novel inhibitors of the Wnt/beta-catenin pathway in breast cancer cells. Eur. J. Med. Chem. 70, 594-606 (2013).

10. Li, Y. Y. \& Shen, Y. M. Secondary metabolites from Phomopsis sp. A123, Mycol. 1, 254-261 (2010).

11. Ma, Y., Wu, X. \& Xiu, Z. Cytochalasin $\mathrm{H}$ isolated from mangrove $\square$ derived endophytic fungus induces apoptosis and inhibits migration in lung cancer cells. Oncol. Rep. 39, 2899-2905. 
(2018).

12. Chen, C., Liang, F. \& Chen, B. Identification of demethylincisterol $\mathrm{A}_{3}$ as a selective inhibitor of protein tyrosine phosphatase Shp2. Eur. J. Pharmacol. 795, 124-133 (2016).

13. Zhou, J., Li, G., Deng, Q., Zheng, D. Y., Yang, X. B. \& Xu, J. Cytotoxic constituents from the mangrove endophytic Pestalotiopsis sp. induce $\mathrm{G}_{0} / \mathrm{G}_{1}$ cell cycle arrest and apoptosis in human cancer cells. Nat. Prod. Res. 32, 1-6 (2018c).

14. Hemphill, P., Francis, C., Daletos, G. \& Liu, Z. Polyketides from the mangrove-derived fungal endophyte Pestalotiopsis clavispora. Tetrahedron. Lett. 3, 101-106. (2016).

15. Zhou, J., Diao, X. P. \& Wang, T. Phylogenetic diversity and antioxidant activities of culturable fungal endophytes associated with the mangrove species Rhizophora stylosa and R. mucronata in the South China Sea. Plos One 13(6), e0197359. (2018b).

16. Jamrozik, E. \& Selgelid, M. J. Surveillance and control of asymptomatic carriers of drugresistant bacteria. Bioethics. 33, 766-775 (2019).

17. Miró-Canturri, A. Ayerbe-Algaba, R. \& Smani Y. Drug Repurposing for the Treatment of Bacterial and Fungal Infections. Front. Microbiol. 10, 41-51. (2019).

18. Tomm, H. A., Lorena, U. \& Ross, A. C. Advances in microbial culturing conditions to activate silent biosynthetic gene clusters for novel metabolite production. J. Ind. Microbiol. Biot. 46, 1381-1400 (2019).

19. Laximanarayan, R. Duse, A. \& Wattal, C. Antibiotic resistance-the need for global solutions. Lancet. Infect. Dis. 13, 1057-1098 (2013).

20. Ghramh, H. A., Khan, K. A. \& Alshehri, A. M. A. Antibacterial potential of some Saudi honeys from Asir region against selected pathogenic bacteria. Saudi J. Biol. Sci. 26, 1-7 (2018). 
21. Wei, C. W., Deng, Q., Sun, M. Y. \& Xu, J. Cytospyrone and cytospomarin: Two new polyketides isolated from mangrove endophytic fungus, Cytospora sp. Molecules, 25, 4224$4233(2020)$.

22. Xu, Z. Y., Wu, X., Li, G, Feng, Z. \& Xu, J. Pestalotiopisorin B, a new isocoumarin derivative from the mangrove endophytic fungus Pestalotiopsis sp. HHL101. Nat. Prod. Res. 34, 1-6 (2018).

23. Buatong, J., Phongpaichit, S., Rukachaisirikul. V. \& Sakayaroj, J. Antimicrobial activity of crude extracts from mangrove fungal endophytes. World J. Microb. Biot. 27, 3005-3008 (2011).

24. Jemal, A., Bray, F., Center, M. M., Ferlay, J., Ward, E. \& Forman, D. Global cancer statistics. CA-Cancer. J. Clin. 61, 69-90 (2011).

25. Kurosawa, S. Anesthesia in patients with cancer disorders. Curr. Opin. Anaesthesiol. 25, 376$384(2012)$

26. Guerrero, O. J. L., Raigon, P. A. \& Malo, M. A. Anesthesia in combination with propofol increases disease-free survival in bladder cancer patients who undergo radical tumor cystectomy as compared to inhalational anesthetics and opiate-based analgesia. Oncology. 98, $161-167$ (2020).

27. Nygren, P., Larsson, R. Overview of the clinical efficacy of investigational anticancer drugs. J. Int. Med. 253, 46-75 (2003).

28. Gupta, S., Chaturvedi, P., Kulkarni, M. G. A critical review on exploiting the pharmaceutical potential of plant endophytic fungi. Biotechnol. Adv. 39, 107462 (2019).

29. He, Q., Zeng, Q. \& Shao, Y. Anti-cervical cancer activity of secondary metabolites of endophytic fungi from Ginkgo biloba. Cancer Biomark. 28, 1-9 (2020) 
30. Romano, S., Jackson, S. A., Patry, S. \& Dobson, A. D. W. Extending the "one strain many compounds" (OSMAC) principle to marine microorganisms. Mar. Drugs. 16, 244-273 (2018)

31. Li, L., Li, D. \& Luan, Y. Cytotoxic metabolites from the antarctic psychrophilic fungus Oidiodendron truncatum. J. Nat. Prod. 75, 920-927 (2012).

32. Takahashi, J. A., Teles, A. P. C.\& Gomes, D. C. Classical and epigenetic approaches to metabolite diversification in filamentous fungi. Phytochem. Rev. 12, 773-789 (2013).

33. Issam, A. A., Zimmermann, S. \& Reichling, J. Antimicrobial activities of European propolis collected from various geographic origins alone and in combination with antibiotics. Medicines. 5, 2-10 (2018).

\section{Acknowledgement}

This work was supported by Finance Science and Technology Project of Hainan Province (ZDKJ202018), National Natural Science Foundation of China (No. 81973229/81660584), High-level Talents Programs of Hainan Province (2019RC006), Key Project of Education Department of Hainan Province (Hnky2019ZD-6), and Research Initiation Fund Project of Hainan University (No. KYQD(ZR)20001) are gratefully acknowledged. 
Table 1 Antimicrobial acticity of the endophytic fungi from R. stylosa

\begin{tabular}{|c|c|c|c|c|c|c|c|c|c|c|c|c|c|c|c|c|c|}
\hline \multirow{3}{*}{ Number } & \multirow{3}{*}{ Species } & \multicolumn{16}{|c|}{$\mathrm{MIC} \mathrm{mo} / \mathrm{mL}$} \\
\hline & & \multicolumn{4}{|c|}{$\mathrm{PDA}{ }^{1}$} & \multicolumn{4}{|c|}{ CZA } & \multicolumn{4}{|c|}{$\mathrm{RM}$} & \multicolumn{4}{|c|}{$\mathrm{GM}$} \\
\hline & & M.A. ${ }^{2}$ & MRSA. & P.A. & E.F. & M.A. & MRSA. & P.A. & E.F. & M.A. & MRSA. & P.A. & E.F. & M.A. & MRSA. & P.A. & E.F \\
\hline HHL70 & Botryosphaeria dothidea & 1 & - & 1 & - & - & - & - & - & & & & & & & & \\
\hline HHL104 & Cladosporium cladosporioides & - & & & - & - & - & - & - & & & & & & & & \\
\hline HHI. 55 & Cytospora rhizophorae & - & 1 & & 1 & - & 0.0625 & 0.031 & - & & 1 & & 1 & & 1 & 1 & \\
\hline HHI 59 & Diaporthe ceratozamiae & - & & & - & - & - & - & - & & 1 & & & & & & \\
\hline HHI .53 & Diaporthe eucalyptorum & - & & & - & - & 1 & - & - & 1 & 1 & & & & & & \\
\hline HнL.61 & Diaporthe perseae & - & & & - & - & - & - & - & 1 & 1 & & & & & & \\
\hline HHL 7 & Diaporthe sp. & & & & - & - & 1 & - & - & & & & & & & & \\
\hline HНI 48 & Fusarium solani & 1 & - & & - & - & - & - & - & & & & & & & & \\
\hline HHI 96 & Guignardia mangiferae & & & & - & & & & & & & & & & & & \\
\hline HНI 31 & Lasiodiplodia ps eudotheobromae & & & & - & & & & & & & & & & & & \\
\hline HHI .94 & Lasiodiplodia theobromae & & 1 & & 0.125 & & 0.125 & 0.125 & & & & & & & & & \\
\hline HHL 129 & Neofusicoccum mangiferae & & 1 & & & & & & & & 0.25 & & & & & & \\
\hline HНI 75 & Neofusicoccum parvum & & & & - & & & & & & 0.25 & & & & & & \\
\hline HHI 46 & Neopestalotiopsis protearum & & & 1 & - & 1 & 0.0625 & & 0.062 & 1 & 0.125 & 0.5 & & & & & \\
\hline HHI 82 & Pestalotiopsis microspora & & & & - & & 1 & 0.125 & & 0.125 & 0.5 & 1 & & 1 & 1 & & \\
\hline HHI .51 & Pestalotiopsis palmarum & & & & - & & & & & & & & & & & & \\
\hline HHI .79 & Pestalotiopsis photiniae & & & & - & & & & & & 1 & & & & & & \\
\hline НHI.10 & Pestalotiopsis sp. & & & & - & & & & & & & & & & & & \\
\hline HHI .56 & Pestalotiopsis theae & & & & - & & & & & & & & & & & & \\
\hline НН, ?.? & Phomopsis asparagi & & & & - & & & & & 1 & & & & & & & \\
\hline HHI. 52 & Phomopsis glabrae & & & & - & & & & & & & & & & & & \\
\hline HHI .50 & Phomopsis longicolla & & & & - & 1 & 1 & & & 1 & 0.25 & & & & & & \\
\hline HНI. 20 & Phomopsis sp. & & & & - & & & & & & & & & & & & \\
\hline HHI 38 & Seiridium ceratosporum & & & & - & & & & & & 0.5 & & & & & & \\
\hline HHL81 & Valsa brevispora & & & & & & & & & 1 & 0.25 & & & & & & \\
\hline
\end{tabular}

${ }^{1}$ Strains were cultivated on four different medium, which were Dextrose Agar (PDA), Czapek's Agar (CZA), Rice Medium (RM) and Grain Medium (GM) from R. stylosa

2 Antimicrobial activites were tested against Gram-negative (Pseudomons adaceae (PA)), Gram-positive (Enterococcus faecalis (EF), Methicillin-resistant Staphylococcus aureus (MRSA))

bacteria and fungi (Monilia albican (MA)) 
Table 2 Antimicrobial acticity of the endophytic fungi from $R$. mucronata

\begin{tabular}{|c|c|c|c|c|c|c|c|c|c|c|c|c|c|c|c|c|c|}
\hline \multirow{3}{*}{ Number } & \multirow{3}{*}{ Species } & \multicolumn{16}{|c|}{$\mathrm{MIC} \mathrm{mg} / \mathrm{mL}$} \\
\hline & & \multicolumn{4}{|c|}{$\mathrm{PDA}^{3}$} & \multicolumn{4}{|c|}{$\mathrm{CZA}$} & \multicolumn{4}{|c|}{ RM } & \multicolumn{4}{|c|}{$\mathrm{GM}$} \\
\hline & & M.A. $^{4}$ & MRSA. & P.A. & E.F. & M.A. & MRSA. & P.A. & E.F. & M.A. & MRSA. & P.A. & E.F. & M.A. & MRSA. & P.A. & E.F. \\
\hline HQD24 & Aspergillus fumigatus & & & & & & & & & & & & & & & & \\
\hline HQD83 & Botryosphaeria fusispora & & & & & & & & & & & & & & & & \\
\hline HOD25 & Colletotrichum gloeosporioides & & 1 & & & & & & & & & & & & & & \\
\hline HOD62 & Diaporthe eucalyptorum & & & & & 1 & - & - & 1 & 1 & & & & & & & \\
\hline HOD33 & Diaporthe pascoei & 1 & & & & & & & & & & & & & & & \\
\hline HOD17 & Diaporthe phaseolorum & & & & & & 0.062 & 1 & 1 & & & & & & & & \\
\hline HกПว9 & Diaporthe sp. & & & & & 1 & & & 0.25 & & 0.125 & & & & & & \\
\hline HOD28 & Eutypella scoparia & & & & & & & & & & & & & & & & \\
\hline HOD48 & Fusarium verticillioides & & & & 0.062 & & & 0.5 & & & & & & & & & \\
\hline HOD72 & Lasiodiplodia theobromae & & 1 & & 0.125 & & 0.125 & 0.125 & & & & & & & & & \\
\hline HOD23 & Neofusicoccum mangiferae & & 1 & & & & & & & & 0.25 & & & & & & \\
\hline HOก 41 & Neofusicoccum parvum & & & & & & & & & & 0.25 & & & & & & \\
\hline HOD.5 & Neopestalotiopsis protearum & & & 1 & - & 1 & 0.062 & & 0.062 & 1 & 0.125 & 0.5 & & & & & \\
\hline HOח55 & Paraconiothyrium hawaiiense & & & & & & & & & & & & & & & & \\
\hline HOD20 & Pestalotiopsis microspora & & & & - & & 1 & 0.125 & & 0.125 & 0.5 & 1 & & 1 & 1 & & \\
\hline HOD1 & Pestalotiopsis protearum & & & & & 1 & & & & & 0.031 & & & & & & \\
\hline HODG & Pestalotiopsis sp. & 1 & 1 & & 0.015 & 1 & & 1 & & 1 & 0.031 & 1 & 1 & & & & \\
\hline HOD57 & Phomopsis glabrae & & & & & & & & & & & & & & & & \\
\hline HกП8 & Phomopsis longicolla & & & & - & 1 & 1 & & & 1 & 0.25 & & & & & & \\
\hline HQD47 & Pseudofusicoccum stromaticum & & & & & & & & & & & & & & & & \\
\hline HQD22 & Valsa brevispora & & & & & & & & & 1 & 0.25 & & & & & & \\
\hline
\end{tabular}

${ }^{3}$ Strains were cultivated on four different medium, which were Dextrose Agar (PDA), Czapek's Agar (CZA), Rice Medium (RM) and Grain Medium (GM) from R. mucronata

4 Antimicrobial activites were tested against Gram-negative (Pseudomons adaceae (PA)), Gram-positive (Enterococcus faecalis (EF), Methicillin-resistant Staphylococcus aureus (MRSA))

bacteria and fungi (Monilia albican (MA)) 
Table 3Anti-tumor activity of endophytic fungi from $R$. stylosa

\begin{tabular}{|c|c|c|c|c|c|c|c|c|c|c|c|c|c|}
\hline \multirow{3}{*}{ No. } & \multirow{3}{*}{ Species } & \multicolumn{12}{|c|}{$\mathrm{IC}_{\mathrm{s} o \mathrm{\mu g} / \mathrm{mL}}$} \\
\hline & & \multicolumn{4}{|c|}{ A549 } & \multicolumn{4}{|c|}{ Hela } & \multicolumn{4}{|c|}{ HepG2 } \\
\hline & & PDA & $\mathrm{CZA}$ & $\mathrm{RM}$ & GM & PDA & $\mathrm{CZA}$ & $\mathrm{RM}$ & GM & PDA & $\mathrm{CZA}$ & RM & GM \\
\hline HHL70 & Botryosphaeria dothidea & & & & & & & & & & & & \\
\hline HHL104 & Cladosporium cladosporioides & & & & & & & & & & & & \\
\hline HHL55 & Cytospora rhizophorae & & & & & & & & & & & & \\
\hline нНL59 & Diaporthe ceratozamiae & - & - & $140.46 \pm 5.61$ & - & & & & & & $26.54 \pm 3.73$ & & \\
\hline HHL53 & Diaporthe eucalyptorum & - & - & - & - & & & & & & & $185.03 \pm 3.22$ & \\
\hline HHL61 & Diaporthe perseae & - & - & $201.04 \pm 1.22$ & - & & & & & & & $23.17 \pm 4.26$ & \\
\hline HHL7 & Diaporthe sp. & & & & & & & & & & & & \\
\hline HHL 48 & Fusarium solani & & & & & & & & & & & & \\
\hline HнL96 & Guignardia mangiferae & & & & & & & & & & & & \\
\hline HнL31 & Lasiodiplodia pseudotheobromae & & & & & & & & & & & & \\
\hline HнL 94 & Lasiodiplodia theobromae & & & & & & & & & & & & \\
\hline HHL 129 & Neofusicoccum mangiferae & & & & & & & & & & & & \\
\hline HHL75 & Neofusicoccum parvum & - & $64.38 \pm 3.40$ & - & - & & $109.77 \pm 1.21$ & & & & $84.23 \pm 1.61$ & & \\
\hline HHL46 & Neopestalotiopsis protearum & - & $144.39 \pm 1.58$ & - & $11.65 \pm 0.34$ & & & $31.03 \pm 1.21$ & & & & $69.15 \pm 1.63$ & \\
\hline HHL 82 & Pestalotiopsis microspora & - & - & $123.35 \pm 1.29$ & - & & & $14.38 \pm 1.84$ & & & & $237.47 \pm 1.75$ & \\
\hline HHL51 & Pestalotiopsis palmarum & & & & & & & $142.77 \pm 1.97$ & & & & & \\
\hline HнL79 & Pestalotiopsis photiniae & & & & & & & & & & & $224.42 \pm 1.43$ & \\
\hline HHL10 & Pestalotiopsis sp. & - & - & $97.21 \pm 1.36$ & - & & & & & & & $39.09 \pm 1.38$ & \\
\hline HHL56 & Pestalotiopsis theae & & & & & & & & & & & & \\
\hline HHL22 & Phomopsis asparagi & & - & $170.84 \pm 1.99$ & - & $341.14 \pm 1.37$ & & & & & & $137.13 \pm 1.71$ & \\
\hline HHL52 & Phomopsis glabrae & & & & & & & $70.55 \pm 1.37$ & & & $33.04 \pm 1.21$ & & \\
\hline
\end{tabular}




\begin{tabular}{|c|c|c|c|c|c|c|c|c|c|c|c|}
\hline HHL50 & Phomopsis longicolla & $192.96 \pm 2.62$ & $108.53 \pm 2.09$ & - & $16.31 \pm 0.36$ & $137.73 \pm 2.53$ & $120.38 \pm 1.79$ & $73.18 \pm 1.64$ & & $55.05 \pm 1.92$ & $177.71 \pm 4.76$ \\
\hline HHL20 & Phomopsis sp. & - & - & $605.5 \pm 1.51$ & - & & & $190.74 \pm 1.39$ & & & $378.08 \pm 1.59$ \\
\hline HHL38 & Seiridium ceratosporum & $386.35 \pm 3.82$ & $151.1 \pm 2.25$ & - & - & & & & $239.82 \pm 1.89$ & & \\
\hline HHL81 & Valsa brevispora & & & & & & & & & & \\
\hline
\end{tabular}

Table 4 Anti-tumor activity of endophytic fungi from $R$. mucronata

\begin{tabular}{|c|c|c|c|c|c|c|c|c|c|c|c|c|c|}
\hline \multirow{3}{*}{ NO. } & \multirow{3}{*}{ Species } & \multicolumn{12}{|c|}{$\mathrm{IC}_{50} \mu \mathrm{g} / \mathrm{mL}$} \\
\hline & & \multicolumn{4}{|c|}{ A549 } & \multicolumn{4}{|c|}{ Hela } & \multicolumn{4}{|c|}{ HepG2 } \\
\hline & & PDA & $\mathrm{CZA}$ & RM & GM & PDA & $\mathrm{CZA}$ & RM & GM & PDA & $\mathrm{CZA}$ & $\mathrm{RM}$ & GM \\
\hline HQD24 & Aspergillus fumigatus & & $179.67 \pm 1.21$ & & & & & & & & & & \\
\hline HQD83 & Botryosphaeria fusispora & $248.17 \pm 1.22$ & $62.63 \pm 1.63$ & $208.13 \pm 1.42$ & $112.17 \pm 1.63$ & & $30.62 \pm 1.21$ & & & $223.05 \pm 1.51$ & $67.73 \pm 1.22$ & & $262.05 \pm 1.45$ \\
\hline HQD25 & Colletotrichum gloeosporioides & $144.89 \pm 1.71$ & & & & & & & & $241.22 \pm 6.19$ & & & \\
\hline HQD62 & Diaporthe eucalyptorum & & & & & & & & & & & $182.03 \pm 1.32$ & \\
\hline HQD33 & Diaporthe pascoei & $109.64 \pm 1.25$ & $23.62 \pm 1.96$ & & & & $214.44 \pm 1.57$ & & & & & & \\
\hline HQD17 & Diaporthe phaseolorum & & & & & $201.66 \pm 1.12$ & & & & & & & \\
\hline HQD29 & Diaporthe sp. & & & & $331.91 \pm 1.33$ & $498.96 \pm 1.66$ & & & & & & & \\
\hline HQD28 & Eutypella scoparia & $53.81 \pm 1.37$ & & & $277.58 \pm 1.30$ & & & & & $14.75 \pm 1.21$ & & $227.03 \pm 1.26$ & \\
\hline HQD48 & Fusarium verticillioides & $547.42 \pm 1.65$ & $4.83 \pm 1.61$ & $34.57 \pm 1.25$ & $106.79 \pm 1.33$ & & $66.78 \pm 1.72$ & & $19.83 \pm 1.13$ & $237.56 \pm 1.2$ & $60.8 \pm 1.29$ & $201.75 \pm 1.47$ & \\
\hline HQD72 & Lasiodiplodia theobromae & & & & & & & & & & & & \\
\hline HQD23 & Neofusicoccum mangiferae & & & & & & & & & & & & \\
\hline HQD41 & Neofusicoccum parvum & & $64.38 \pm 1.23$ & & & & $109.77 \pm 1.22$ & & & & $84.23 \pm 1.63$ & & \\
\hline HQD5 & Neopestalotiopsis protearum & & $144.40 \pm 1.75$ & & $11.65 \pm 1.03$ & & & $31.03 \pm 1.21$ & & & & $69.15 \pm 1.63$ & \\
\hline HQD55 & Paraconiothyrium hawaiiense & & & & & & & & & & & & \\
\hline HQD20 & Pestalotiopsis microspora & & & $126.73 \pm 1.21$ & & & & $14.38 \pm 1.84$ & & & & $237.47 \pm 1.75$ & \\
\hline HQD1 & Pestalotiopsis protearum & & $40.09 \pm 1.39$ & & $119.65 \pm 1.38$ & & $186.85 \pm 1.67$ & & & & & & \\
\hline HQD6 & Pestalotiopsis sp. & $28.90 \pm 1.26$ & & $14.99 \pm 1.62$ & & & & & & $196.17 \pm 1.65$ & & $9.58 \pm 0.01$ & \\
\hline HQD57 & Phomopsis glabrae & & & & & & & & & & $33.04 \pm 1.21$ & & \\
\hline
\end{tabular}




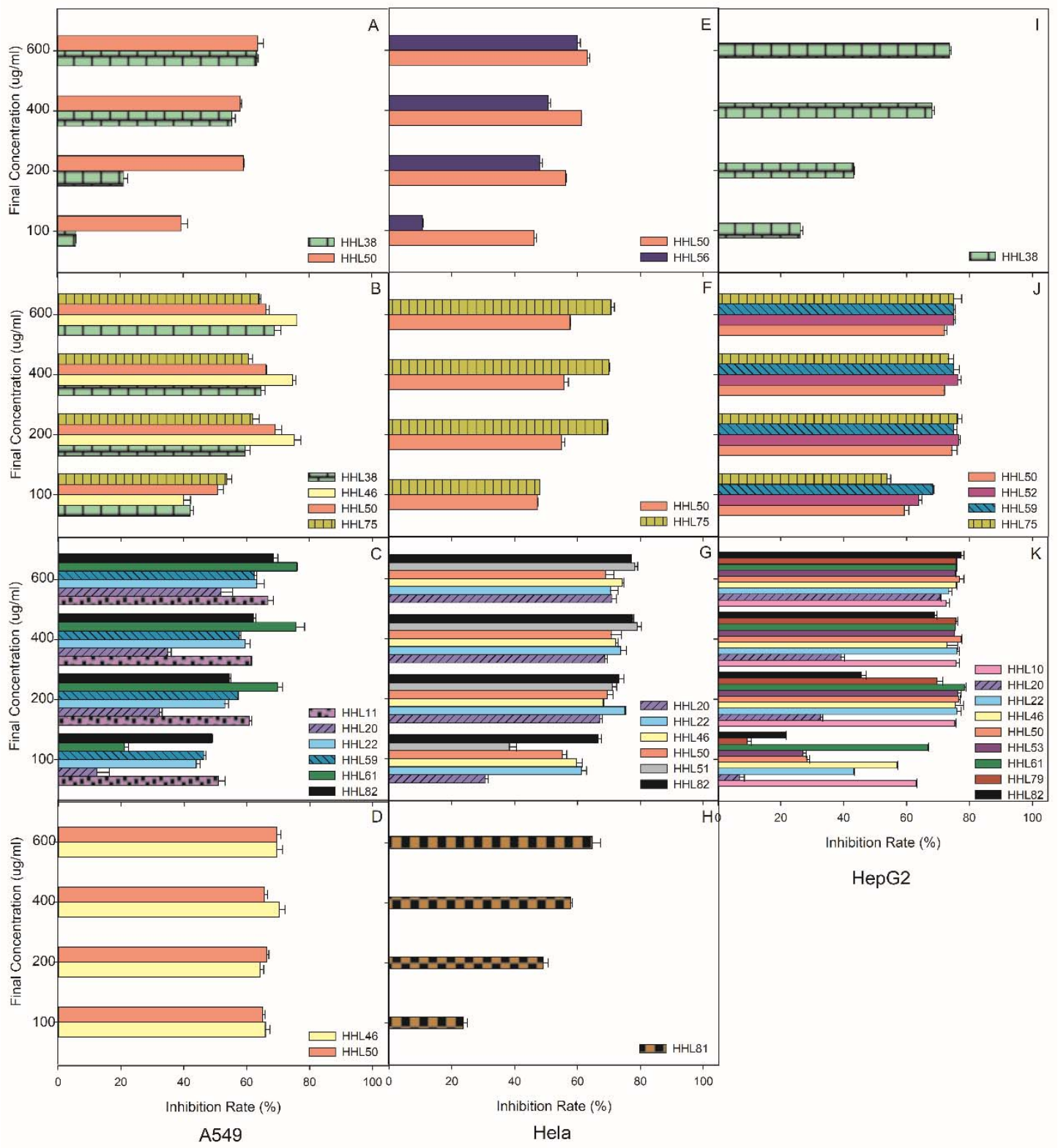

Fig. 1Anti-tumor activity of endophytic fungi from $R$. stylosa 


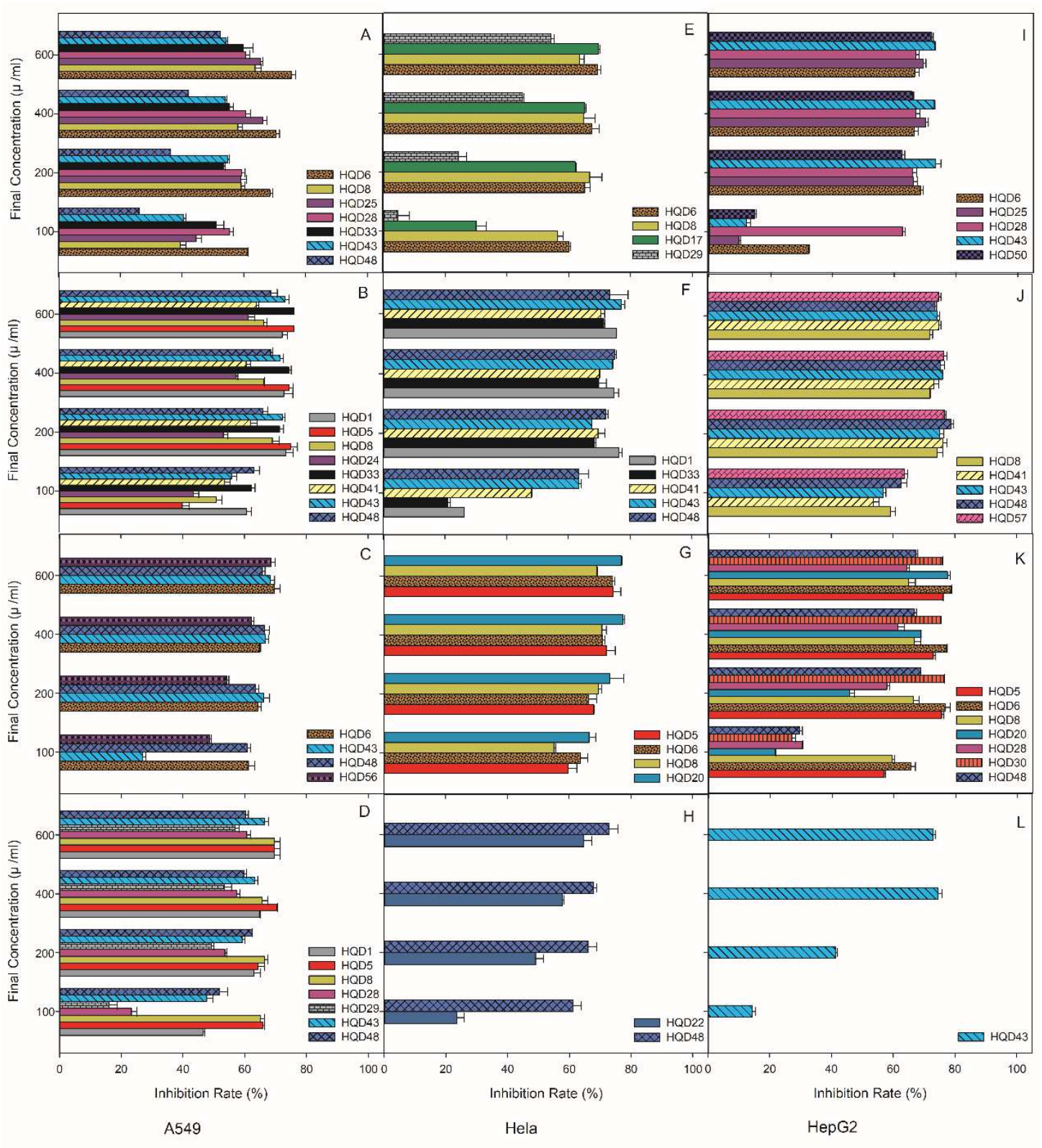

Fig. 2 Anti-tumor activity of endophytic fungi from $R$. mucronata 


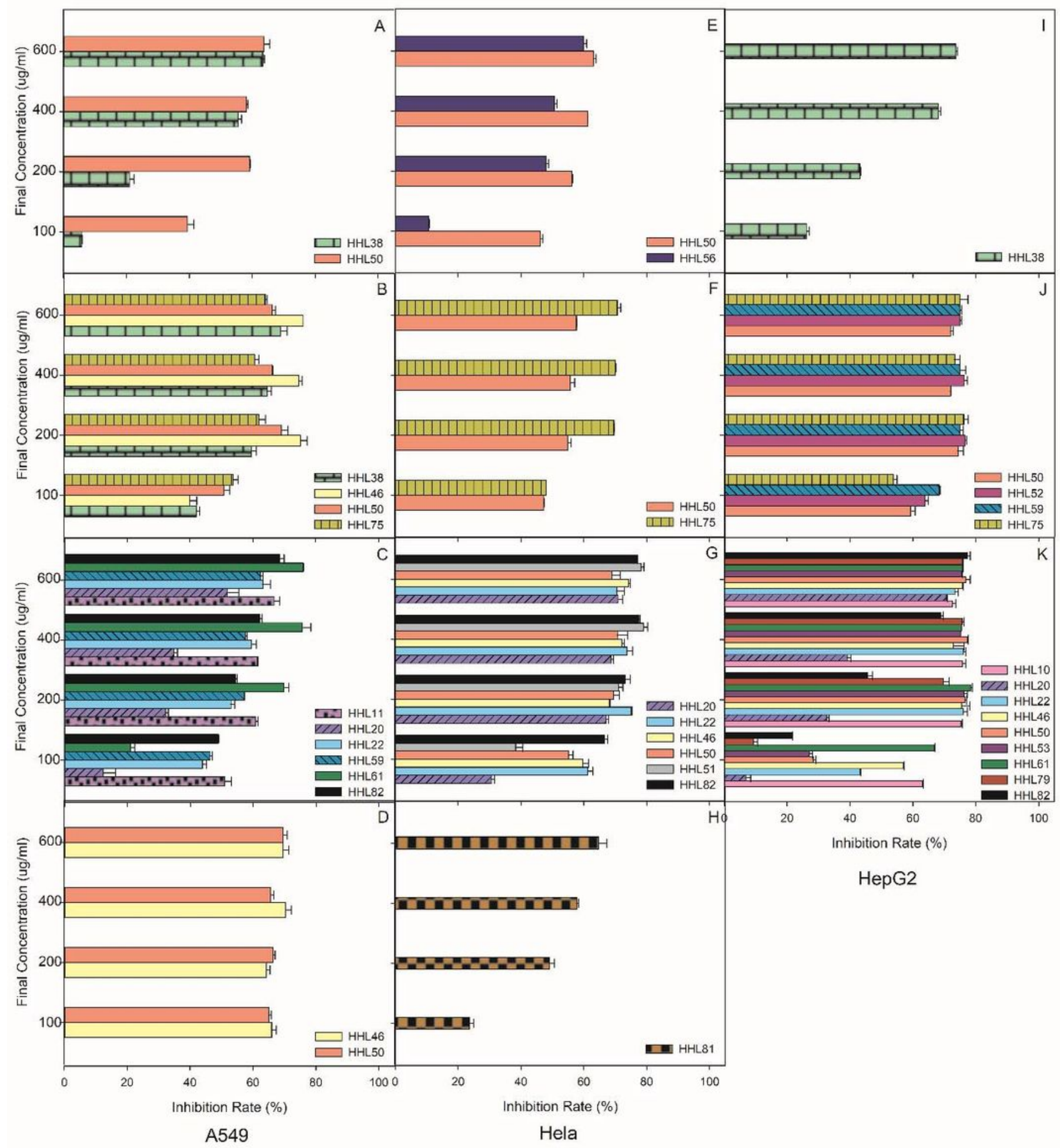

\section{Figure 1}

Anti-tumor activity of endophytic fungi from R. stylosa 


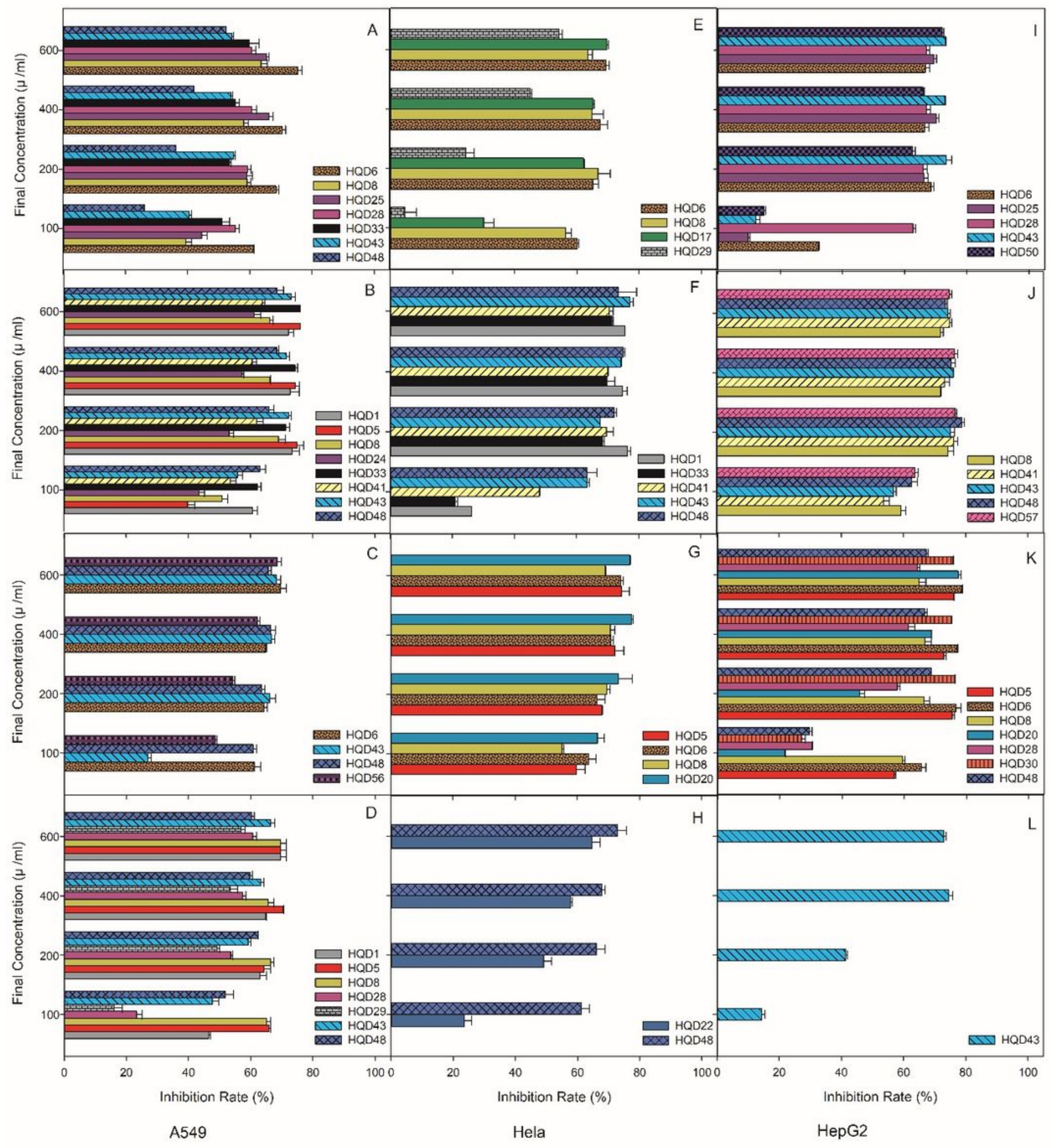

Figure 2

Anti-tumor activity of endophytic fungi from R. mucronata 